University of Wollongong

Research Online

Faculty of Engineering and Information

Faculty of Engineering and Information

Sciences - Papers: Part A

Sciences

2000

Developments in blast furnace process control at Port Kembla based on process fundamentals

Robert Nightingale

BHP Steel, robertn@uow.edu.au

Rian Dippenaar

University of Wollongong, rian@uow.edu.au

Wei-Kao Lu

McMaster University

Follow this and additional works at: https://ro.uow.edu.au/eispapers

Part of the Engineering Commons, and the Science and Technology Studies Commons

Research Online is the open access institutional repository for the University of Wollongong. For further information contact the UOW Library: research-pubs@uow.edu.au 


\title{
Developments in blast furnace process control at Port Kembla based on process fundamentals
}

\author{
Abstract \\ This article is based on a presentation made in the "Geoffrey Belton Memorial Symposium," held in \\ January 2000, in Sydney, Australia, under the joint sponsorship of ISS and TMS.

\section{Keywords} \\ port, control, developments, process, blast, kembla, fundamentals, furnace \\ Disciplines \\ Engineering | Science and Technology Studies

\section{Publication Details} \\ Nightingale, R. J., Dippenaar, R. J. \& Lu, W. (2000). Developments in blast furnace process control at Port \\ Kembla based on process fundamentals. Metallurgical and Materials Transactions B, 31 (5), 993-1003.
}




\title{
Developments in Blast Furnace Process Control at Port Kembla Based on Process Fundamentals
}

\author{
ROBERT J. NIGHTINGALE, RIAN J. DIPPENAAR, and WEI-KAO LU
}

\section{THE BLAST FURNACE PROCESS}

THE iron blast furnace is in principle a countercurrent gas/solid heat exchanger from tuyere raceway to stockline and a countercurrent oxygen exchanger from fusion zone to stockline.${ }^{[1]}$ Solid raw materials consisting of iron ore, sinter, coke, and fluxes are charged into the top of the furnace, while air, and sometimes hydrocarbons and oxygen, is blasted through tuyeres near the bottom of the furnace. The retention time of the ore may be as long as 8 hours, while that of the gas is a few seconds. However, the residence time of the coke in the hearth is longer, varying from 1 to 4 or more weeks. ${ }^{[2]}$ The liquid hot metal and slag products are tapped at regular intervals through several tapholes near the bottom of the furnace. The slag is separated from the metal and the liquid metal is transported to the steel plant.

In an attempt to gain a better understanding of this complex process in which direct experimental measurement is exceedingly difficult, experimental as well as operating furnaces have been quenched and dissected. Earlier studies by Bosley et al..$^{[3]}$ and Muravev et al. ${ }^{[4]}$ were followed by very detailed and comprehensive investigations in Japan. The results of these studies have been fully documented, summarized, and thoroughly analyzed by a committee of the Iron and Steel Institute of Japan. ${ }^{[5]}$ Largely based on the information gained from these dissections, it has been possible to divide the modern blast furnace for the sake of convenience and further discussion into five different zones. ${ }^{[1,6]}$

(1) lumpy zone (upper stack and cyclic reduction zone),

(2) cohesive zone (softening and melting zone),

(3) active coke zone,

(4) Hearth-Deadman, and

(5) tuyere raceways.

The verification of the existence of a cohesive zone through the dissection of quenched furnaces gave an enormous boost to blast furnace operational improvements. In this zone, the first slag forms, ferrous materials soften, and melting begins. In the cyclic reduction zone, carbon monoxide reacts with wustite to produce solid iron and carbon dioxide. The carbon dioxide, in turn, reacts with coke to regenerate carbon monoxide and this cycle prevails at temperatures above $1000{ }^{\circ} \mathrm{C}$. Excess carbon monoxide reduces hematite and magnetite to wustite in the upper stack.

ROBERT J. NIGHTINGALE, Superintendent of Ironmaking Development, is with BHP Steel, Port Kembla, NSW2505, Australia. RIAN J. DIPPENAAR, Director, is with the BHP Institute for Steel Processing and Products, University of Wollongong, Wollongong, NSW2522, Australia. WEI-KAO LU, Professor Emeritus, is with the Department of Materials Science, McMaster University, Hamilton, ON, Canada L8S 4L7.

This article is based on a presentation made in the "Geoffrey Belton Memorial Symposium," held in January 2000, in Sydney, Australia, under the joint sponsorship of ISS and TMS.
In the hearth, refining of the liquid metal and final reduction and separation of the liquid slag and metal occur as well as the final carburization of the iron. In the raceway region, oxygen in the incoming hot-blast air reacts with carbon to produce carbon dioxide as well as heat and, subsequently, carbon monoxide. Intensive heating and reduction take place in the active coke zone as well as in the zone of the coke percolators. The role that this near stationary zone, which is often referred to as the deadman, plays in effective blast furnace operations has been clearly highlighted and its significance in modern, large furnaces has been verified. ${ }^{[5]}$

The dissection of blast furnaces clarified in much more detail than before the importance of the cohesive zone, the nature of the flow of gas through the coke slits in the cohesive zone, and the nature of the chemical reactions in the furnace. It further drastically altered the very concept of the process. These advances generated, in turn, a demand for improved blast furnace instrumentation ${ }^{[5]}$ and the concomitant process control. Poos ${ }^{[7]}$ reiterated these sentiments by pointing out that blast furnace control panels of the 1950s were so rudimentary that they informed staff of only a few variables such as stockline movement, blast pressure, and temperature. The furnaces of that period had to be relined frequently; the availability was below 75 pct of calender time. That was 50 years ago. However, in the last 25 years, tremendous strides have been made in the optimization of the process. In general, the productivity of furnaces has increased, not only due to careful control but also to increased blast temperature, oxygen enrichment, increased top pressure, improved quality control of raw materials, size, and size distribution control of raw material and burden distribution control. ${ }^{[1,6]}$

The modern blast furnace is characterized by a large hearth diameter, hindering the flow of gas as well as liquid metal and slag through the deadman and hearth. The raceway penetrates only to a depth of $2 \mathrm{~m}$ into the furnace so that gas flow is more directed to the periphery as the hearth diameter increases and, hence, the percentage active area diminishes with an increase in hearth diameter. In a blast furnace with a hearth diameter of $4 \mathrm{~m}$, the active ring covers the full area at the level of the raceway. However, the active area reduces to less than 50 pct if the hearth diameter increases to $14 \mathrm{~m} \cdot{ }^{[8]}$ Because of this variance in the radial direction, the ability to manage and control gas flow and gas distribution, therefore, is relatively more important in big furnaces. The large inactive zone in the furnace also impacts on the ability to drain the metal and slag, especially with regard to maintaining core temperature and permeability.

\section{ADVANCES IN CONTROL}

The development of reliable, rapid, and affordable techniques to sample and analyze the liquid product streams 
enabled the first significant advances in process control. Since these streams have long residence times and were still infrequently sampled, strategies based on simple feedback were quite limited. Control abilities were next improved with the advent of continuous top gas analysis technology. The far shorter residence time of the gas stream gave a valuable improvement in both the response time and the ability to close mass and energy balances on the process.

The conceptual advances derived from quenched furnace investigations have since been enhanced by the development of an array of sophisticated probes. Fixed probes monitor the radial temperature distribution of the top gas stream. Profile meters measure the placement of raw materials at the stockline, and retractable intrusive probes routinely measure the radial variation in gas temperature and composition within the lumpy zone.

Today, comprehensive computer based heat and mass balance modeling techniques are used to control the state of the furnace in real time. Operators are also supported by online models describing burden distribution and cohesive zone formation. ${ }^{[9]}$

\section{EMERGENT CHALLENGES}

Business realities continue to demand that the blast furnace process be operated at increasing standards of process safety and stability, hot metal quality, and frequently increased productivity.

In order to achieve this, it is becoming increasingly important to control the whole process. This necessarily includes the region below the cohesive zone where the presence of liquid phases adds greater complexity. The physical conditions of operating pressure and temperature in this region make the online use of retractable probes prohibitively difficult and expensive for general application. The notable exception is at NSC Oita, ${ }^{[10]}$ where a massive watercooled probe is available. This device represents a large capital outlay and its infrequent mode of use limits data analysis. This is especially true in times of difficult operations when it is not used for safety reasons. These are, of course, the most important conditions to investigate.

Probings of the coke bed through the tuyeres at shutdown are widely practiced. Unfortunately, online probing at sensible cost and frequency is impractical. At Port Kembla and elsewhere, ${ }^{[11,12]}$ these offline efforts confirm the "aliveness" and critical importance of the deadman through observed, and all too often, inadequately explained variation in condition. These probes provide a good snapshot but they are costly, and sample processing is so time consuming that the acquired data cannot be used for any real time process control.

Undoubtably, the greatest and largely unaddressed challenges are those associated with the understanding and management of the condition and flow of the coke bed in the furnace deadman and hearth. The fundamental properties of this process stream are critical, but the literature contains little or no discussion on measured change in these properties over time nor on modeling of responses to fluctuation in voidage or cleanliness (fines contamination) of this coke bed.

To allow constructive interpretation of furnace performance in response to variations in the coke bed, a continuous supply of data relating to the permeability of the coke bed (especially to liquid streams) is required. Further, methods for interpreting the data and for implementing timely control practices need to be developed. These practice initiatives may involve modifications to raw material properties or to furnace operating indexes.

\section{INTERACTIONS BETWEEN LIQUIDS AND THE SLOW MOVING COKE BED}

\section{A. The Coke Bed}

Following discharge from the lower surface of the cohesive zone, metal and slag droplets drain through a packed coke bed before collecting in the furnace hearth. Coke bed contact continues for finite but differing times for each collected phase before removal from the furnace hearth.

The coke lumps in this part of the furnace are the survivors of the physical and chemical rigours of prior handling and passage through the upper parts of the furnace. As such, the coke bed is expected to dynamically reflect changes in input coke quality. These are usually derived from variations in the coal blend and its preparation and to changes in coking battery operating practice. Adjustments to blast furnace feed conditions (e.g., alkali loadings) and operating intensity may also influence coke degradation. The level of process stability required for viable contemporary operation dictates that changes such as these occur infrequently.

As a result, changes in the coke bed of the blast furnace deadman and hearth generally occur over days and weeks. This behavior is reinforced by the solid flow dynamics of the process itself and this has been confirmed by quenched furnace investigations, ${ }^{[13,14,15]}$ use of radioactive isotopes, ${ }^{[16]}$ and laboratory modeling ${ }^{[17]}$ in addition to widespread anecdotal evidence.

The presence of fine solid particles impairs the permeability of a fixed or slow moving bed by increasing the fluidsolid contact area and friction forces. In the case of the blast furnace deadman, three sources of fine material may broadly be identified. The first is fines carried down from above where they may have been introduced with the charge. They may also be the result of volume and surface breakage responses to the forces of the lumpy and cohesive zones. In the case of coke, there may also be the abraded products of surface weakening due to the carbon solution loss reaction.

The second potential source of fines is the unfluxed oxide particles. Species such as $\mathrm{SiO}_{2}, \mathrm{Al}_{2} \mathrm{O}_{3}, \mathrm{TiO}_{2}, \mathrm{CaO}$, and $\mathrm{MgO}$ or particles extremely rich in these species are generally solid at deadman temperatures. Solid particles may be deposited from dripping slags, which still contain a dispersed solid phase at discharge. Additionally, oxide particles may be precipitated by dripping slags where $\mathrm{FeO}$ serves as the flux. In such cases, subsequent removal of the $\mathrm{FeO}$ on reaction with contacted coke particles raises the liquidus temperature of the remaining slag until solidification occurs. This behavior is possible with both highly acidic and highly basic slags, but is more likely to be a problem with highly acidic $\mathrm{SiO}_{2}$ or $\mathrm{TiO}_{2}$ based slags due to their much lower reducibility. Highly basic slags are likely to drip with very low residual $\mathrm{FeO}$ contents. Solid oxide particles can be dynamically removed by dissolution into the compositionally suitable contacting slag droplets. This mechanism also serves to dissolve solid ash from the surface of coke particles.

The third source of solids is the coke in raceways. These 
carbonaceous fines may be coke debris or incompletely combusted char from pulverized coal injection. Raceway gases carry these particles into the deadman and the active coke zone. The behavior of these particles may vary widely depending on their size, the chemical reactivity of the carbon, and the nature of associated oxide (ash) phases. Because gas velocities in the deadman are lower than in the active coke zone (especially near the furnace center) the deposition of larger particles, often those derived from coke, is a particular threat in this region. The deposition of graphite (kish) from tiny droplets of iron expelled from the furnace raceway is also possible since sites remote from the raceway are at considerably lower temperature. Graphite is variably observed in shutdown tuyere coke probings, and this may reflect the fact that the probability of its deposition is greater in an operation with unstable heat balance.

\section{B. The Liquids}

The blast furnace ferrous burden is most commonly a mixture of up to five discrete materials. Of these, the most commonly used is sinter, which is itself an inhomogeneous agglomerate of diverse fine ores and fluxes. While some mixing of these materials always occurs (and is often promoted), individual solid particles generally give rise to separate liquid dripping products. Therefore, the furnace deadman represents a highly heterogeneous reaction environment as droplets of metal and slag move through the coke bed and through gradients of temperature and reduction potential. While laboratory experiments have been devised to study the meltdown behavior of individual and mixed ferrous materials, very little is known about the behavior or mixing of molten products within the deadman.

The collected pools of metal and slag in the furnace hearth represent a much more homogeneous condition, but still the opportunity for heterogeneous reaction exists as the metal droplets pass though the slag layer, at the interfacial surface and at contact surfaces with the coke.

\section{The Interactions}

When the coke bed in the blast furnace deadman has high permeability, the dripping metal and slag products move rapidly into the hearth under the influence of gravity. The individual transit time may, of course, vary with viscosity in the case of slag droplets.

When liquids pass through the coke bed in the deadman/ hearth, there are three types of reaction: i.e. coke/metal, coke/slag, and metal/slag reactions. In these heterogeneous reactions, the kinetics of reaction depends on the area of contact and the time of contact of reacting phases. Proper treatment of these heterogeneous reactions may be found elsewhere ${ }^{[18]}$ For the present work, it is sufficient to consider the following reactions.

Carburization:

$$
\mathrm{C}(\text { coke })+\mathrm{Fe}(1) \rightarrow \text { hot metal }
$$

When this reaction is completed, hot metal becomes saturated with carbon, the value being determined by temperature.
Reduction of oxides in slag:

$$
\mathrm{C}(\text { coke })+\mathrm{FeO}(\text { slag }) \rightarrow[\mathrm{Fe}](\text { hot metal })+\mathrm{CO} \text { (gas) }
$$

and

$$
\mathrm{C}(\text { coke })+\mathrm{MnO}(\text { slag }) \rightarrow[\mathrm{Mn}](\text { hot metal })+\mathrm{CO} \text { (gas) }
$$

and

$\mathrm{C}($ coke $)+\frac{1}{x} \mathrm{TiO}_{x}($ slag $) \rightarrow \frac{1}{x}[\mathrm{Ti}]($ hot metal $)+\mathrm{CO}($ gas $)$

It is well known that these reactions do not reach equilibrium states in the blast furnace hearth.

The extent of completion of these reactions depends on many factors, mainly properties of the coke bed and reaction conditions such as temperature, contact time, and chemical composition of each phase.

Slag/metal reactions are mainly replacement reactions; i.e., cations such as $\mathrm{Mn}^{2+}$ in slag is replaced by a solute in hot metal (eg. $1 / 2 \mathrm{Si}^{4+}$ ) or the anion $\mathrm{O}^{2-}$ is replaced by $\mathrm{S}$ and two electrons from hot metal. The coke bed affects slag/ metal reactions by promoting the mixing of the two reacting phases and/or lengthening the time available for reaction.

When the deadman coke bed is dirtied, the transit of all liquids is prolonged and the opportunities for gas/metal, coke/metal, and metal/slag reactions to proceed toward equilibrium are increased.

Let us start with an excellent hearth practice; i.e., the deadman is very permeable and all liquids above the taphole (for the simplicity of argument) are drained during each cast. There are many causes which may lead to the beginning of the deterioration of permeability of the deadman. For example, switching to weaker coke and/or less reducible ore; increasing the generation of fines in the raceways; losing the control of burden distribution; etc. The common consequences of these changes are the widening of the size distribution of coke and the decreasing of its average size. The less permeable coke bed of the deadman has smaller and fewer passages for liquid flows and exercises larger drag force (due to larger solid-liquid contact area) to hinder these flows. A drop in temperature in the hearth would cause viscosities of liquids to increase and therefore hinder liquid flows. With an increase in the production rate of liquids, with the same casting schedule, the tapping rate has to increase, which requires a more permeable deadman. Under essentially the same operating conditions, the gradual deterioration of the permeability of an excellent deadman will lead to slower flow rate of liquids inside the deadman, i.e., the hearth. Therefore, with the same casting practice, an equivalent degree of liquid removal ("dryness") can no longer be achieved. Gradual increase in the amount of liquids retained in the hearth means greater risk from excessive liquid level in the case of any operating delay and/or higher probability of wind volume (productivity) loss due to decreased furnace permeability. Of course, if we know that the permeability of the deadman is decreasing, then certain countermeasures can be adopted.

Analysis techniques based on the extent of departure from equilibrium states can yield valuable information on the state of the coke bed in the furnace deadman and hearth. Previous studies, most notably those of Tsuchiya et al. ${ }^{[19]}$ have related departures from equilibrium for the partition of silicon, manganese, and sulfur between metal and slag phases to the 
internal state of the furnace without making any reference to the state or variation of the deadman coke bed. Their effort appeared to be aimed at minimization of the fuel rate rather than process monitoring and control as in the present work. Tsuchiya et al. define partition reaction attainment to equilibrium ratios, $R_{\mathrm{Si}}=\left(L_{\mathrm{Si}} / L_{\mathrm{Si}}^{0}\right) 100, R_{\mathrm{Mn}}=\left(L_{\mathrm{Mn}} / L_{\mathrm{Mn}}^{0}\right) 100$, and $R_{\mathrm{S}}=\left(L_{\mathrm{S}} / L_{\mathrm{S}}^{0}\right) 100$, where $L_{i}$ is the partitioning ratio calculated from the process data and $L_{i}^{0}$ the equilibrium ratio. They used the tapping slag composition and explained $R_{\mathrm{Si}}$ behavior in terms of the height of the furnace coke reserve zone and the resultant reaction opportunity for silicon transfer to the hot metal by the accepted primary mechanism involving $\mathrm{SiO}$ gas. This explanation of "thermal intensity" is undoubtedly viable. Kinetic considerations for heterogeneous reactions relating to the status of the coke bed in the hearth were not included.

In the cases of $R_{\mathrm{Mn}}$ and $R_{\mathrm{S}}$, Tsuchiya et al. observed that the kinetics of manganese and sulfur transfer reactions,

$$
\left(\mathrm{Mn}^{2+}\right)+2 e \rightarrow[\mathrm{Mn}] \text { and }[\mathrm{S}]+2 e \rightarrow\left(\mathrm{S}^{2-}\right)
$$

are more retarded when slag containing more residual $\mathrm{FeO}$ enters the hearth to result in more of the following reaction:

$$
\left(\mathrm{Fe}^{2+}\right)+2 e \rightarrow \mathrm{Fe}
$$

Under the conditions that raw materials' quality was essentially constant, they therefore relate these indexes to burden descent stability. Again, the explanations made are sound in fundamental terms and, in the case of sulfur, consistency with laboratory results is noted. However, the authors did not discuss the possibility for variable extents of reaction during dripping to influence manganese and sulfur transfer directly or to influence the $\mathrm{FeO}$ load on the hearth.

If the permeability deteriorates from bad to worse, the situation changes rather differently. The flow through the deadman becomes too slow to be effective, particularly for larger blast furnaces. Then, liquids from the active coke zone have to find their own "path of least resistance". An increased amount of liquid will flow through the region of high voidage, i.e., the gap between the "impermeable" deadman core and the refractory sidewall. It is clearly more risky to bring additional liquid iron (which is hot and undercarburized) and slag (which is oxidizing and contains alkali oxides) in direct and close contact with carbon refractories.

\section{The Carburization}

The departure from equilibrium, which allows a direct connection with the internal state of the furnace, is that for carbon dissolution. This is because the information is carried by the metal stream alone. This stream, while derived from all the ferrous burden materials, is relatively uniform at the time of discharge when compared to the often highly diverse dripping slags. The high density and low viscosity of the metal also minimize the opportunity for factors other than the nature of the coke bed to influence kinetics of carburization.

Within the volume below the cohesive zone, a condition of supply and demand exists for carbon. The saturation limit is determined by the temperature of the hot metal and the presence of other solute elements. The carbon to be supplied is determined by the initial content of the dripping hot metal (i.e., burden mix dependent), the reactivity of the carbon sources present, ${ }^{[20]}$ the available contact time, and the surface area of contact.
In a blast furnace regime characterized by stable coke quality, injectant load, burden mix, tuyere conditions, casting, and burden distribution practices, it is to be expected that the supply/demand balance will be essentially maintained. Until recently, ${ }^{[21]}$ it has been widely assumed that the driving force and time available for carbon dissolution are sufficient to ensure that saturation is the norm if not the rule. In fact, hot metal tapped from the blast furnace is almost always not saturated, and in general, the greater the departure from saturation, the better the internal condition and performance of the furnace. Carbon subsaturation of 0.2 pct or greater is observed for a clean deadman.

Once this nonsaturated state is recognized, the degree of departure from equilibrium may be used to study the furnace response to a change in any of the previously listed variables determining carbon supply and demand.

In order to maintain high deadman permeability, it is necessary that dripping metal consistently consumes fine carbonaceous material. Of course, dripping metal contacts survivor coke particles as well and dissolves carbon from these too. It follows that when metal drains rapidly through the clean deadman, it does little damage to the deadman coke lumps and arrives in the hearth with a carbon appetite able to promote hearth cleanliness and renewal with sound coke. When the dripping metal is retained in a low permeability deadman, it causes damage to the deadman coke and arrives in the hearth with little appetite to remove any fines. The hearth coke bed renewal is retarded, and when it is renewed, it is by previously damaged deadman coke. Therefore, once the deadman is dirtied, recovery is often very difficult and prolonged.

Since messages carried by the composition of the metal and slag streams relate to phenomena occurring in the whole of the volume below the cohesive zone, it is only possible to loosely ascribe locational variations in condition when significant and sustained variations are observed between liquid streams tapped from individual tapholes. The only other information available is that for the voidage condition of the coke bed at the discrete level of the taphole level, which can be estimated in continuous fashion by calculations based on casting data as discussed elsewhere. ${ }^{[22]}$

\section{DECODING MESSAGES CARRIED BY LIQUID FLOWS AT PORT KEMBLA}

Once it is understood that the status of the deadman coke bed is implicated in the hot metal carbon content, other messages about the behavior of dripping slags can be inferred from the partitioning behavior of certain elements. These behaviors also depend on the condition of the coke bed through which the slag must also drip.

\section{A. Metal Signals}

The amount of carbon required for saturation is determined by the metal temperature and the concentration of other elements also dissolved in the liquid iron. Interactions between solute species occur at the atomic level and marked changes in solute activities can arise. However, the linear approximation of Eq. [1] has been found to be adequate.

At Port Kembla, an expression developed by Neumann et al. $^{[23]}$ is used. This considers, that carbon saturation in 
iron containing small amounts of silicon, sulfur, phosphorous, and manganese is used to determine the carbon content at saturation. The expression has the form

$$
\begin{aligned}
\text { pct } \underline{\mathrm{C}}_{\text {sat }}= & 1.3+2.57 \times 10^{-3} \mathrm{~T} \\
& -0.31 \text { pct } \underline{\mathrm{Si}}-0.33 \text { pct } \underline{\mathrm{P}} \\
& -0.4 \text { pct } \underline{\mathrm{S}}+0.028 \text { pctMn }
\end{aligned}
$$

All concentrations are in mass percent and temperature is in degrees Celsius. Although variations in the concentration of the other elements such as titanium must be acknowledged as potential sources of error, these have not proven to have a debilitating effect on the application of this expression.

The departure of hot metal carbon content from the saturation value, $\Delta C$, is readily determined.

$$
\Delta \underline{C}=\text { pet } \underline{C}_{\text {sat }}-\text { pet } \underline{C}_{\text {actual }}
$$

Because dirtying of the deadman by slag is also possible, the hybrid deadman cleanliness index (DCI) has been developed by combining the temperature sensitive term of Eq. [1] and the $\Delta C$ value with an expression describing sensitivity of the liquidus temperature of the Port Kembla tapped slag to its lime/silica basicity index.

$$
\begin{aligned}
\mathrm{DCI} & =\mathrm{HMT}+\frac{1}{2.57 * 10^{-3}} \Delta \underline{C} \\
& -(1430-190 *(1.23-C / S))
\end{aligned}
$$

where $\mathrm{HMT}=$ hot metal temperature and $\mathrm{C} / \mathrm{S}=$ the $\mathrm{CaO} /$ $\mathrm{SiO}_{2}$ ratio of the tapped slag. The constant $2.57 * 10^{-3}$ is a conversion factor from the unit of concentration to the unit of temperature; the liquidus temperature at $C / S=1.23$ is $1430{ }^{\circ} \mathrm{C}$.

While there is little doubt that information on the primary or dripping slags would be preferable, the previously expression has proven to be of greater utility in the Port Kembla circumstance than the $\Delta C$ value alone. ${ }^{[21]}$

Dirtying of the deadman by raceway coke debris deposition can occur as a result of coke quality deterioration or inappropriate increase in kinetic energy of the blast at the tuyeres. Both conditions can be illustrated by operating data. The former condition is illustrated with daily average (average of approximately 40 metal samples per day) in Figure 1 , where coke of inferior quality was charged to the Port Kembla No. 6 Blast Furnace for a period of several days immediately prior to an extended maintenance shutdown on February 22, 1997. The deterioration in DCI was immediate, extreme, and prolonged with full recovery taking 12 months. During this period, tuyere coke probe samples were taken at the initial shutdown and on two subsequent occasions (June 30 and October 28). Results for DCI, coke particle size, and metal and slag retention at a depth of $2 \mathrm{~m}$ from the tuyere nose are shown in Table I. Progressive improvements in hearth coke and liquid drainage at the standard sampling time after shutdown are associated with increasing values of DCI. These should be compared with the value of 170 previously (and eventually later) experienced with good quality coke and equivalent operations.

Once the deadman is dirtied by carbon fines in this way, the removal can only occur by dissolution of the carbon in the hot metal and reactions with slag.
The influence of excessive blast kinetic energy is illustrated with daily average data in Figure 2, where operational data for both Port Kembla furnaces are presented. In each case, deadman cleanliness suffered immediately from the time when increased tuyere velocity occurred as the result of operating with small back-up blowing engines.

Dirtying of the deadman coke bed by freezing of slag or unmelted ore is demonstrated in Figure 3, again using daily average data. The DCI decreased sharply on the introduction of titania bearing and unfluxed ore $\left(52\right.$ pct $\mathrm{Fe}_{2} \mathrm{O}_{3}, 33$ pct $\mathrm{TiO}_{2}, 4$ pct $\mathrm{SiO}_{2}$ ) to the No. 5 Blast Furnace in November 1988. This was charged to achieve a titania loading rate of $12 \mathrm{~kg}$ per tonne of hot metal in order to provide protection to the hearth refractories. No other significant change to furnace operations occurred in November, and it is clear that the residue of the titania bearing ore, which may or may not melt, impaired the permeability of the coke bed. It should be noted that equivalent titania loading rates had been charged via ilmenite/cement bricks ( 37 pct $\mathrm{Fe}_{2} \mathrm{O}_{3}, 33$ pct $\mathrm{TiO}_{2}, 5$ pct $\mathrm{SiO}_{2}, 7$ pct $\mathrm{Al}_{2} \mathrm{O}_{3}, 7$ pct $\mathrm{CaO}$ ) since February 1988 with little impact on DCI, and the dripping slag does not appear to have suffered resolidification problems.

\section{B. Slag/Metal Signals}

Droplets of metal and slag must pass through the same coke bed to reach the furnace hearth. Figure 4 shows daily average data indicating that the partition ratios for manganese and titanium are highly correlated with DCI. Each index data is presented in daily average form and involves approximately 40 metal and 12 slag samples per day. The behavior displayed is typical and is clearly consistent with the proposal that all these indexes can be used to routinely monitor changes to the permeability of the coke bed that is common to the passage of both phases. A drop in DCI value corresponds to a closer approach toward the equilibrium condition for both carburization and the reduction of metal oxides from slag. Changes occurring due to variations in the coke quality and operational disruption may be monitored in this way.

In 1984 to 1986 , there were changes made to the iron bearing raw materials used at Port Kembla. In this period, the variations in titanium and manganese partitions were rather different. Sinter has always supplied the bulk $(\sim 70$ pct) of the ferrous burden, complemented by smaller quantities of pellets and lump ores. These materials are repeatedly combined at the stockhouse to provide the same ferrous layer at all levels of the furnace stack. Considerable mixing of the materials within each layer also occurs on the charging belt conveyor and during passage through the furnace charging elements.

In July $1985, \mathrm{a} \mathrm{TiO}_{2}$ and $\mathrm{MgO}$ bearing pellet was introduced into the furnace burden replacing lump ore. This pellet replaced sinter and coke as the main sources of titania. Figure 5 shows daily average data for the blast furnace titania loading, the hot metal temperature, the titania partition ratio, and DCI for the period from June 1984 to December 1986. High values of the $\mathrm{Ti} / \mathrm{TiO}_{2}$ prior to the end of 1984 were associated with higher concentrations of coke ash and the presence of some titania minerals in the ash. Analysis records for the ferrous burden streams were incomplete until 1985. Fluctuations in $\mathrm{Ti} / \mathrm{TiO}_{2}$ ratio during 1984 to 1985 are consistent with (inversely correlated to) DCI fluctuations. From 


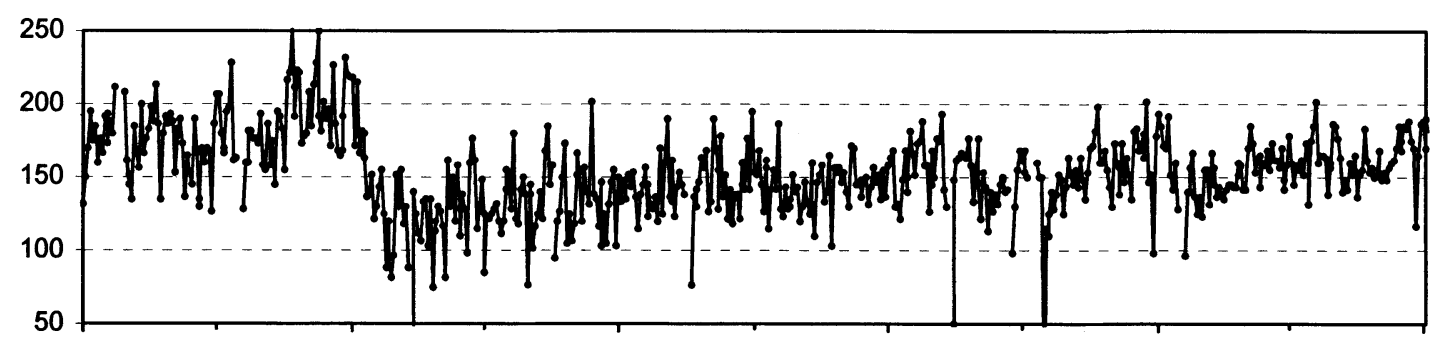

\section{Coke DI 150/15 (\%)}

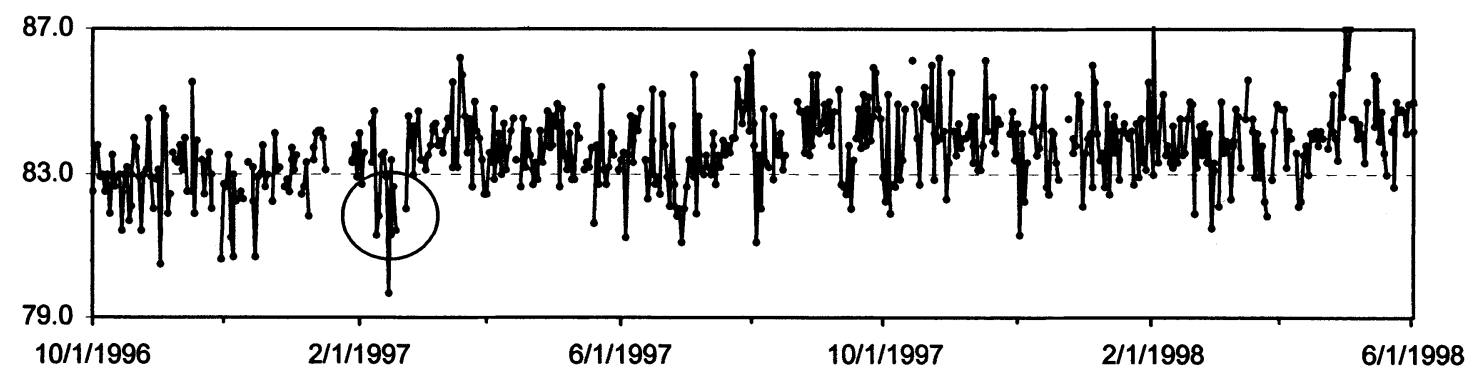

Fig. 1-Extended recovery of Port Kembla No. 6 Blast Furnace from a period of poor coke quality coincident with an extended shutdown (circled).

Table I. Results of Tuyere Coke Probe Sampling No. 6 Blast Furnace

\begin{tabular}{lccc}
\hline & \multicolumn{3}{c}{ Shutdown Date } \\
\cline { 2 - 4 } & $22 / 02 / 97$ & $30 / 06 / 97$ & $28 / 10 / 97$ \\
\hline DCI & 126 & 144 & 157 \\
Pct-8-mm coke & 53 & 26 & 7 \\
Pct-4-mm coke & 32 & 17 & 5 \\
Mean coke size (mm) & 14 & 26 & 37 \\
Pct metallics & 17 & 3 & 11 \\
Pct slag & 17 & 8 & 2 \\
\hline
\end{tabular}

November 1985, the aim hot metal temperature was deliberately reduced and this was accompanied by decreases in both $\mathrm{DCI}$ and $\mathrm{Ti} / \mathrm{TiO}_{2}$. The former is to be anticipated from Eq. [3], while the latter is consistent with the reduced thermodynamic driving force resulting from lower operating temperatures. Some increased variability of both the hot metal temperature and the partition ratio is evident throughout 1986.

The utility of DCI as an indicator of overall furnace performance is demonstrated in Figure 6, where unedited data in the form of monthly averages is presented for the entire current campaign of Port Kembla No. 5 Blast Furnace (June 1991 to present). Hot metal silicon and, in particular, its standard deviation provide the best available indicators of thermal and process stability.

The significant correlation of the latter with DCI is particularly constructive. The fuel rate provides the most complete available measure of process efficiency, while the total stave heat load measures not only a significant component of process energy loss but also a very major determinant for campaign life.

\section{Further Observations}

It is also possible for the deadman to become dirtied by an imbalance between carbon fines supply and demand due to diminished carbon appetite of the hot metal. This can occur in instances where aim hot metal temperature is reduced or where the ferrous burden materials and operating condition generate higher carbon contents in liquid iron at meltdown.

Additionally, difficulties in maintaining deadman cleanliness can be intensified by increased metal concentrations of those elements that decrease the saturation carbon content of the metal, notably silicon, phosphorous and sulfur (Eq. [1]). In the case of silicon, the consequence of the usage of lump quartzite as a flux stone should be recognized, since it has been shown that under Port Kembla circumstances, some 43 pct of the silicon in lump quartzite reports directly to the hot metal. ${ }^{[24]}$ In the case of sulfur, very low concentrations (less than $0.010 \mathrm{pct}$ ) may also be problematic, since the kinetics of carbon dissolution are significantly increased for some materials in very low sulfur melts. ${ }^{[25]}$ Under this condition, the dripping metal may dissolve most carbon from lump coke particles in the active coke zone and little in the deadman. The average hot metal sulfur level at Port Kembla is 0.014 pct.

In order to retain a healthy appetite for coke debris, char, or graphite from the raceway, the lump coke itself should have a low carburizing ability. This is quite opposed to recent suggestions by Gudenau et al. ${ }^{[26]}$ The inherent ability of the coke to carburize the hot metal (e.g., the amount of ash and its properties and distribution) can also impact on the ability to keep the deadman clean.

During any blast furnace shut down, compaction of the burden materials occurs after the upward force of the gas flow is removed. Maintenance shutdowns at Port Kembla 
No. 5 Blast Furnace

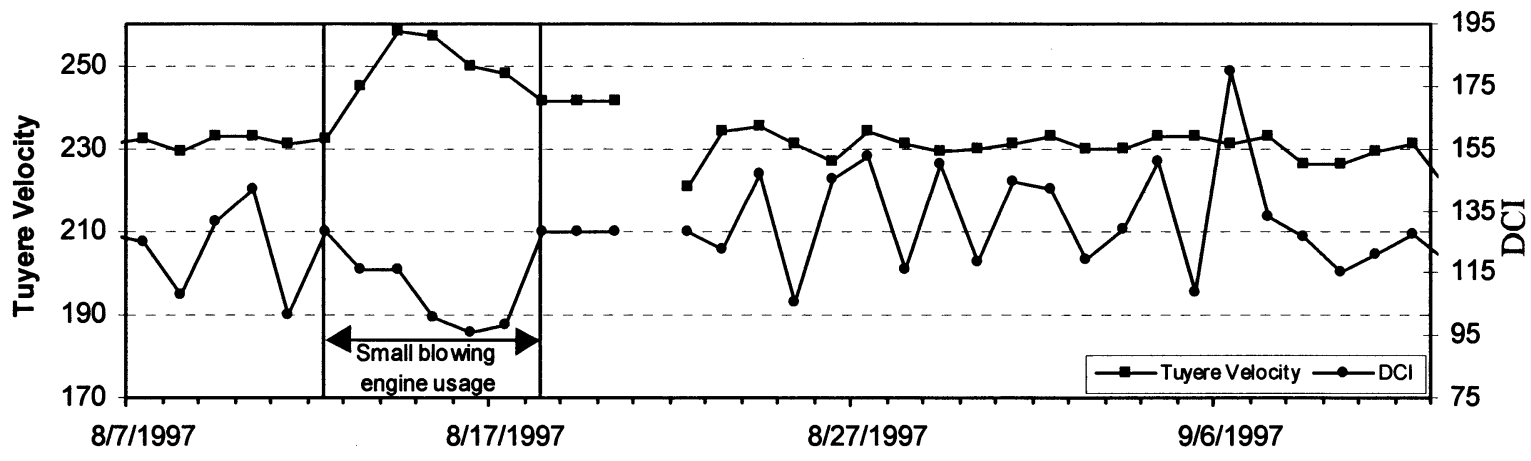

No. 6 Blast Furnace

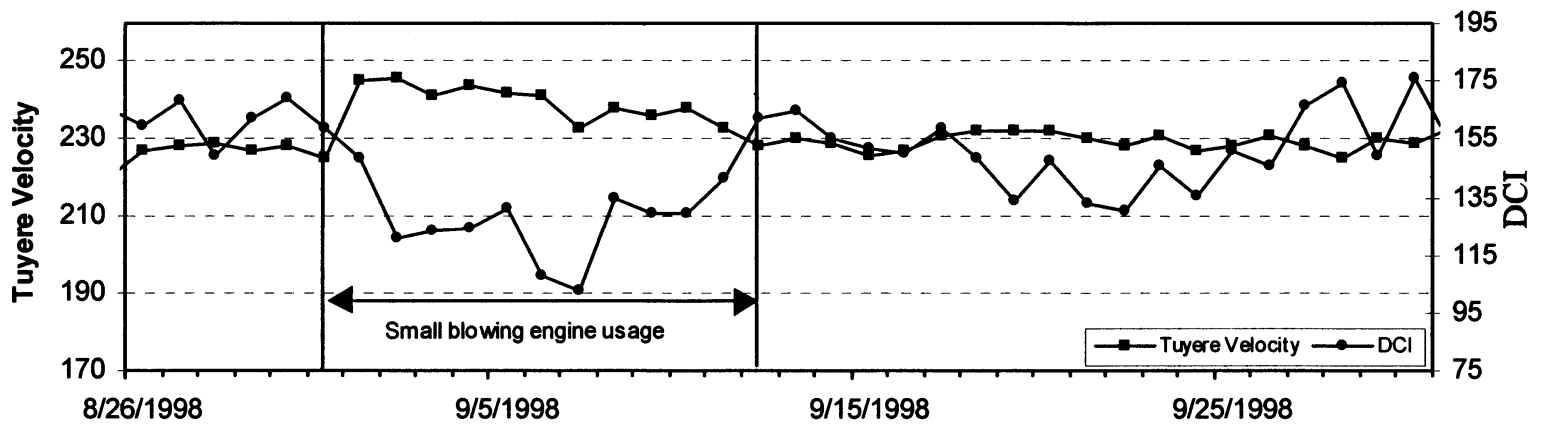

Fig. 2-DCI responses to periods of increased tuyere velocity. Port Kembla Nos. 5 and 6 Blast Furnaces.

$\mathrm{DCl}$

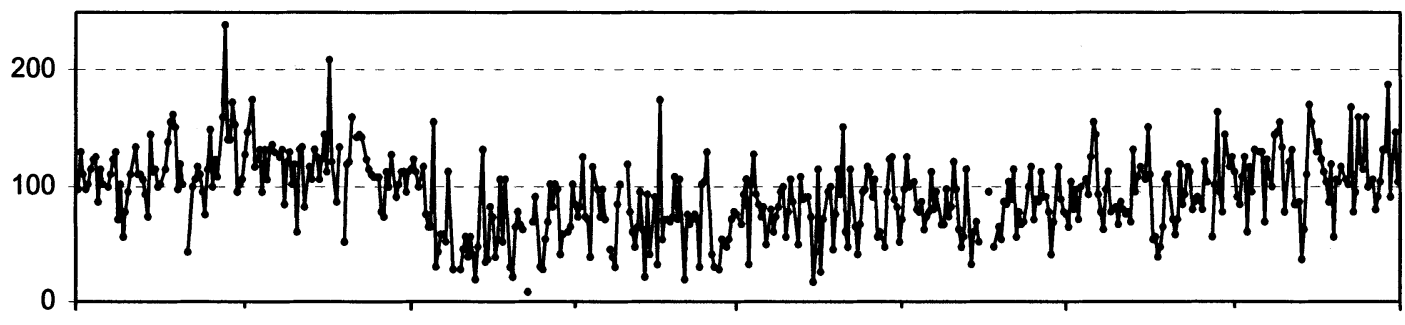

Titania Ore (Tonnes/Day)

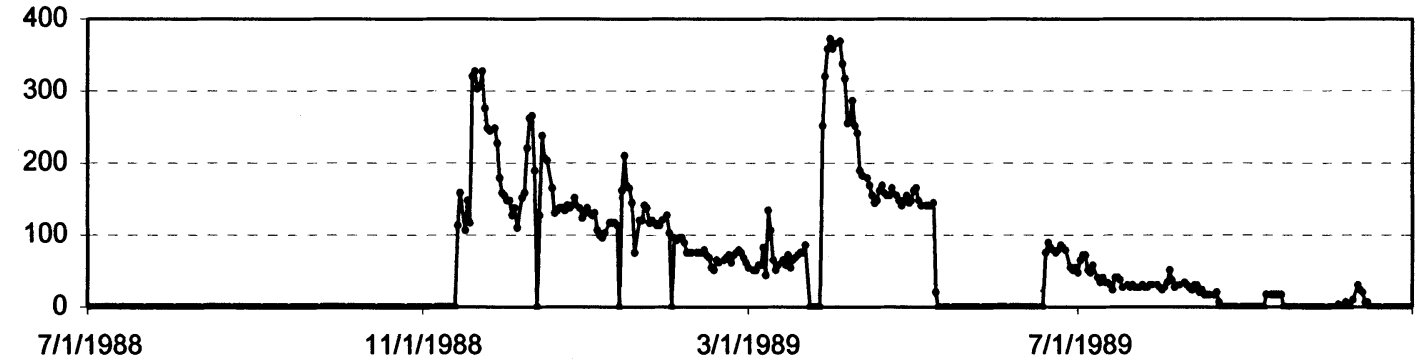

Fig. 3-DCI response to the charging of titania ore. Port Kembla No. 5 Blast Furnace.

are typically of 36 or more hours duration. During this time, a decrease of the burden stock line of $1 \mathrm{~m}$ or more is commonly observed. This compaction accumulates across the full height of the furnace contents. Recovery from compaction takes a much longer time in the volume of the deadman due to the weight of material above and the much lower rate of material turnover in this zone. During extended shutdowns, thermal losses also increase the probability of retarded slag movement and even resolidification in post startup operations. Following shutdowns, it is generally 


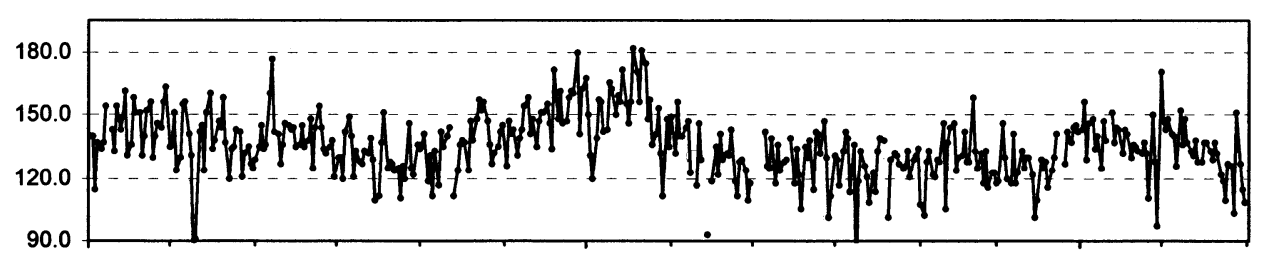

$\triangle \mathrm{C} \%$ (Sat - Actual)

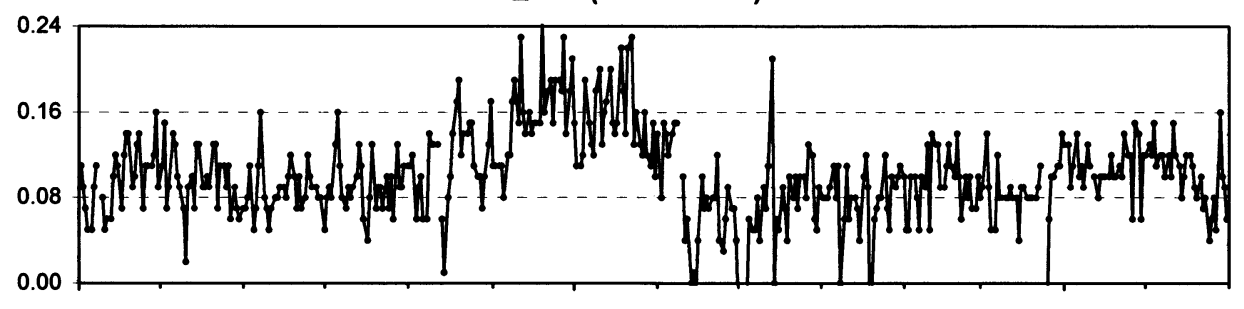

Metal/Slag Mn/MnO

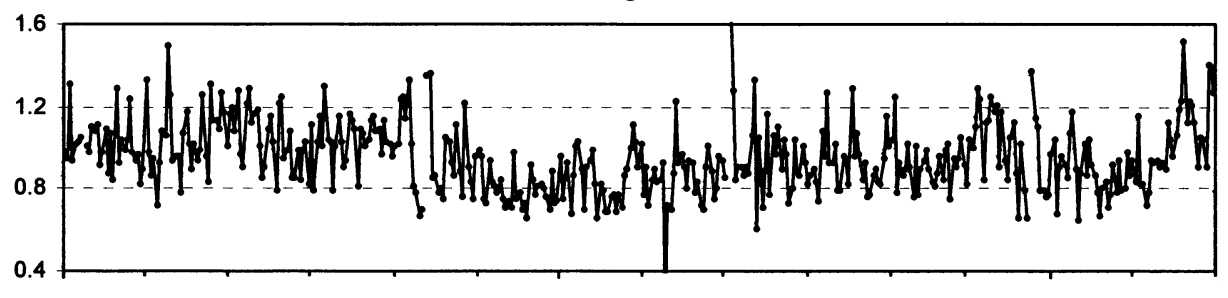

Metal/Slag $\mathrm{Ti}^{\mathrm{TiO}} \mathrm{T}_{2}$

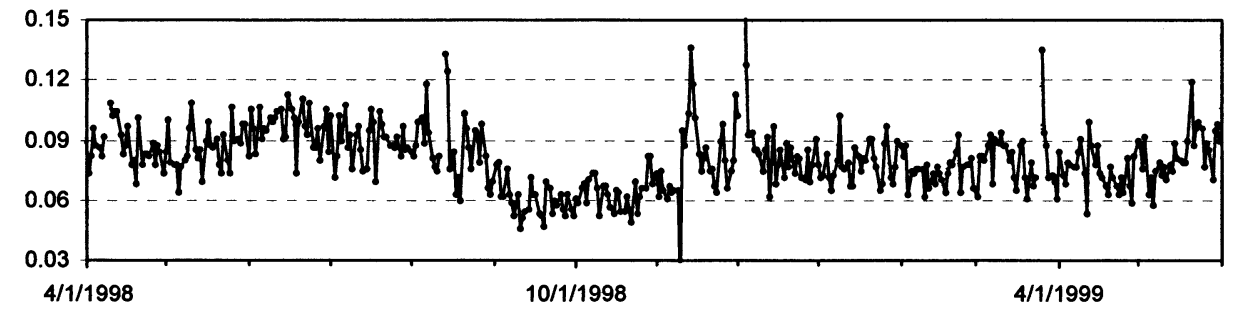

Fig. 4-Comparison between DCI and partition ratios for manganese and titanium. Port Kembla No. 5 Blast Furnace.

observed that the DCI and partition ratio deteriorations extend for a period of several days beyond the full recovery of hot metal temperature. This demonstrates the physical nature of compromised permeability.

In addition to the ability to confirm DCI trends relating to transient deadman condition, metalloid partition ratios can occasionally be studied over the longer term to provide some understanding about the behavior of primary or dripping slags. The composition of these slags often differs greatly between raw material types. Where the input furnace loading of any particular partitioning element is heavily and consistently derived from a particular material, the partitioning ratio may provide useful insights into the behavior of the dripping slag from that material.

\section{DISCUSSION}

In the chain of steps of processing raw materials to hot metal, the weak link appears to be in the deadman-hearth region. The sophistication and effectiveness in the control of quality of raw materials, burden distribution, fuel injection, and tuyere practice reflect advances in our knowledge about physical and chemical phenomena in those other regions of the blast furnace. The present work is aimed to shed some light on the regions below the cohesive zone where there is no direct means to monitor the inner state. The most critical part of this region is the coke bed through which liquids flow.

The data presented here have indicated that there is significant information, which reflects the state of the deadman 

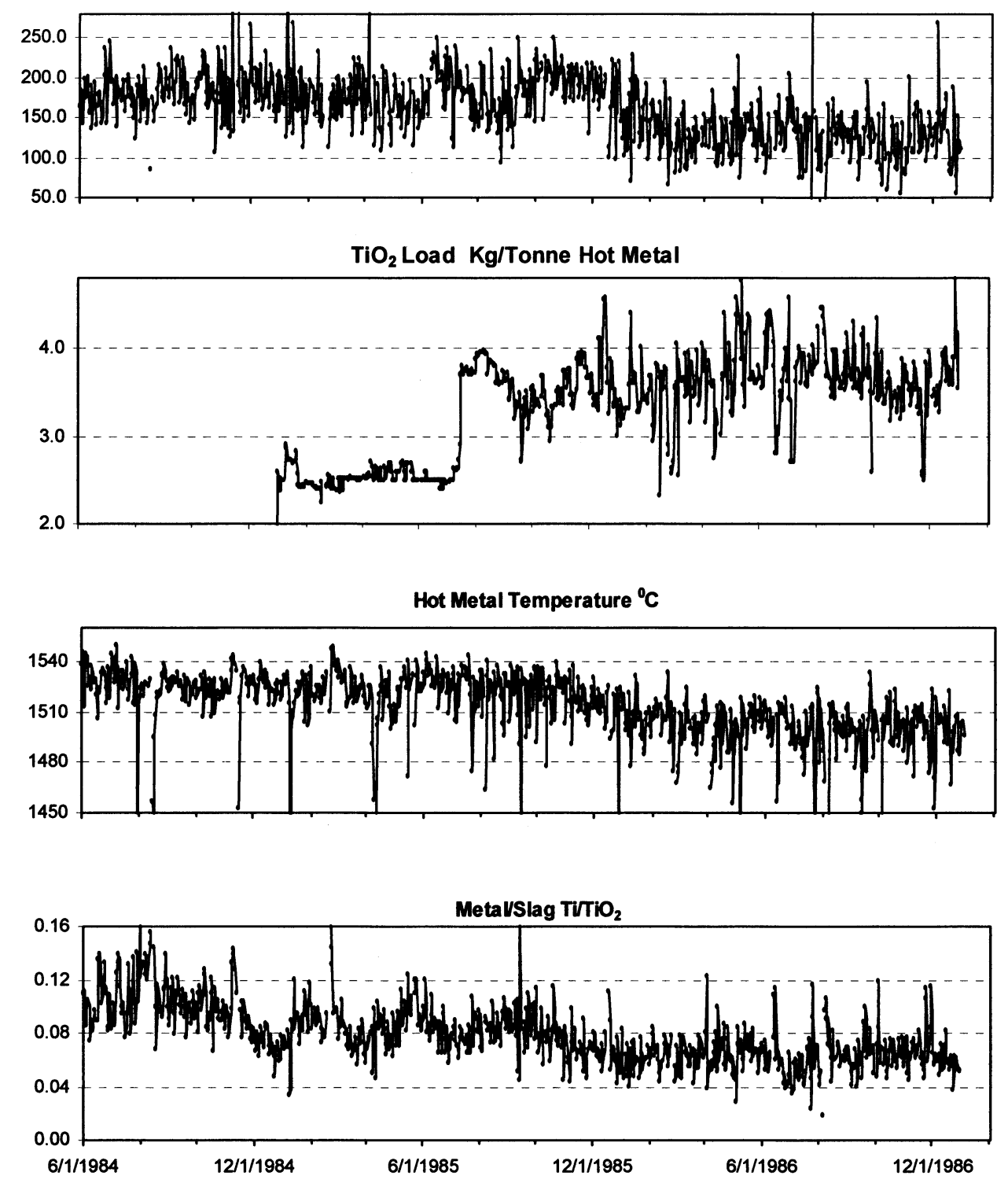

Fig. 5-Responses of DCI and titanium partition ratio to decreased metal temperature. Port Kembla No. 5 Blast Furnace.

and hearth, carried out in tapped hot metal and slag. An index, DCI, based on properties (i.e., daily average of temperature and chemical compositions) of hot metal and slag is proposed as an indicator of the properties of the deadman hearth. The most important property of the coke bed is liquid permeability, which is sensitive to the average size and size distribution of coke pieces and trapped oxide particles.

As a performance indicator, the usefulness of DCI has been demonstrated. In Figure 6, particularly, the correlation with silicon standard deviation indicates the relevance to process stability. The partition of manganese and titanium is shown in Figure 4.

Factors that cause DCI to change are shown in Figures $1,2,3$, and 5. These factors determine the packing (properties of solids) of the coke bed; i.e., they present a mechanism for changes of permeability of the deadman. By accepting this mechanism, which is of course subject to further refinement when more data become available, operators know what to expect at the time an adjustment is made.

The concept of a dynamic balance of the rate of generation of fines in the lumpy zone and raceways and the rate of consumption of fines in the deadman by hot metal and slag is very important in the control of hearth condition. The thermodynamic driving force and kinetic factors for the flowing liquids to eliminate carbonaceous and oxide fines are important and complex; however, they will not be a part of this article. One must keep in mind the fact that the operator does not have an effective tool (as the gas flow is for the other part of the blast furnace) to correct conditions in the hearth. Once the deadman is impaired, it takes a long time, weeks and months, to recover, so the protection of the deadman should have high priority. 


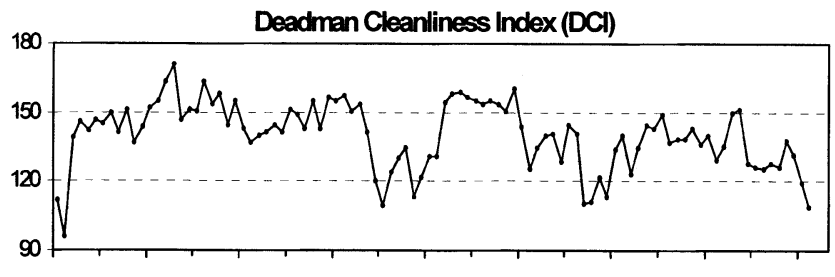

Metal \% Si

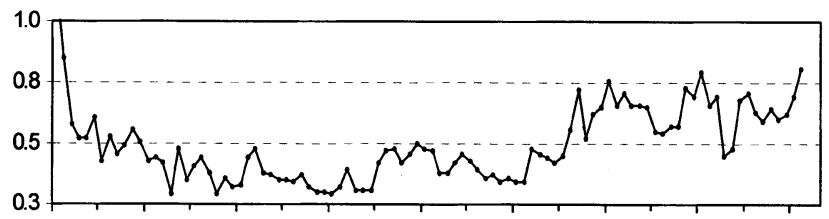

SDMatal \% Si

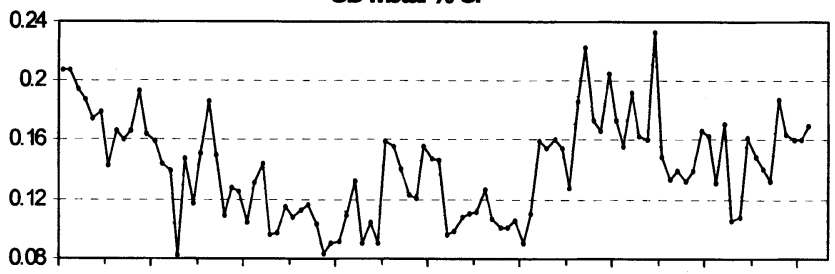

Fuel Rate Kg/Tonne Hot Metal

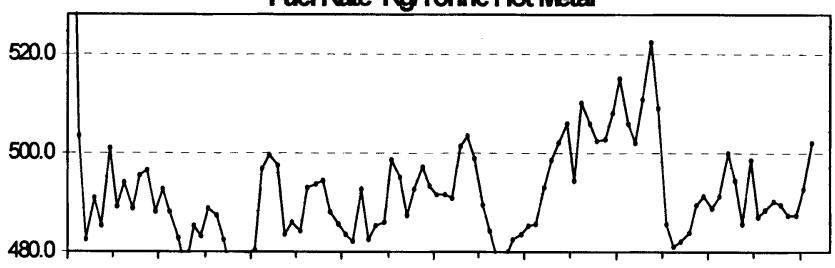

Total Stave Heatload (GMay)

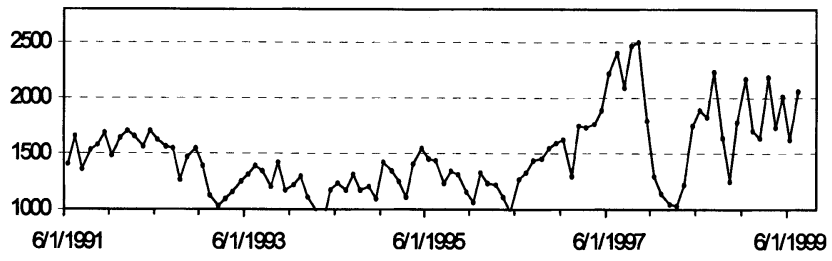

Fig. 6-Comparison between DCI and key operating indices. Current campaign of Port Kembla No. 5 Blast Furnace.

Our understanding of hearth phenomena through the evaluation of DCI as presented in the present work is preliminary; however, it provides the physical basis for the development of mathematical models of hearth and casting practice. With newly gained knowledge of hearth phenomena, the whole blast furnace process becomes more or less transparent, i.e., without a blind spot. It might be the time to investigate and to establish the required quality of raw materials and charging practice for a given operating condition. The interplay between modeling and observations will advance the technology of blast furnace ironmaking and lead to more efficient commercial operations.

\section{FOCUS OF CURRENT EFFORTS}

As a result of information derived from DCI based studies, a number of process modifications have already been made at Port Kembla. Aim operating temperatures have been increased. Tuyere diameters are being increased to reduce blast kinetic energy. Coal blending and coal preparation activities have been adjusted to significantly improve coke performance in the furnace.

Current developmental activities also include laboratory investigations to identify the expected carbon content of hot metal droplets discharged from the cohesive zone for each burden material in use. Mixtures of materials and sinters representing development opportunities are also being examined. This is a simple and logical extension of existing methods for studying the softening/melting behaviors of these materials.

Research activities into coke quality are also now drawing on DCI based learnings to explore new opportunities.

The lessons that can be derived from observation of DCI and partition coefficients are extremely powerful because of their fundamental basis. The signals are sometimes quite noisy and require significant and appropriate filtering. Furthermore, these signals are inherently capable of reporting on two or more concurrent process influences. For these reasons, the task of message decoding is not straightforward and the selection and filtering of data from suitable and significant periods of operation continues to prove crucial.

As significant new data and behaviors are identified, they are being systematically incorporated into a sophisticated mathematical model of the process. These constitute important improvements since the state of the hearth and deadman have previously been the most crudely modeled zones of the process. Sensitivity studies using the upgraded model are now being used to identify areas for prioritized developmental focus and to identify new questions that can then be tested against the real process data sets. Continued interplay and validation activities of this nature are expected to generate advances in effective control of the hearth and deadman, and ultimately in the whole of the ironmaking process.

\section{CONCLUSIONS}

The DCI developed at Port Kembla is based on the undersaturation of carbon in iron and the superheat of slag.

Experience with DCI has clearly shown that superior blast furnace performance is associated with higher values of this index.

By studying DCI responses to coke quality and operating conditions, the critical importance of continually limiting and consuming the quantity of carbonaceous debris from the raceways and trapped oxide particles has been recognized. Strategies to implement these learnings continue, and development activities to improve coke and ferrous material qualities are now being guided by DCI at Port Kembla.

Partition ratios of manganese and titanium are strongly correlated to DCI and confirm that these fundamentally based indices can also be used to continuously monitor the condition of the lower zones of the furnace. Additionally, where the total furnace load of a particular partitioning element is predominantly derived from a single raw material, the behavior of the partition coefficient can allow conclusions to be drawn about the behavior of the dripping slag derived from that material.

Observations from Port Kembla suggest that little mixing 
of primary slags occurs in the deadman and that most liquid mixing occurs in the hearth pools.

\section{ACKNOWLEDGMENTS}

We are grateful to the Management of BHP Steel for encouragement in this work and permission for its publication. The many constructive suggestions and conversations of Port Kembla Ironmakers must also be acknowledged. In particular, the statistical and data management support provided by Kevin Price has been invaluable.

\section{REFERENCES}

1. J.G. Peacey and W.G. Davenport: The Iron Blast Furnace Theory and Practice, Pergamon Press, Elmsford, NY, 1979.

2. M. Kondo, Y. Konishi, H. Koitabashi, Y. Morioka, S. Hasizume, H. Takahashi, K. Okumura, and S. Tomita: Tetsu-to-Hagané, 1978, vol 64, p. S546.

3. J.J. Bosley, N.B. Melchen, and M.M. Harris: J. Met., 1959, Sept., pp. 610-15.

4. V.M. Muravev and N.I. Mischenko: Stahl Eng., 1970, pp. 591-94.

5. Blast Furnace Phenomena and Modelling, Committee on Reaction within Blast Furnace, Joint Society on Iron and Steel Basic Research, The Iron and Steel Institute of Japan, Elsevier Applied Science, New York, NY, 1987.

6. W.-K. Lu: 6th Int. Iron and Steel Congr., Nagoya, Oct. 21-26, 1990, The Iron and Steel Institute of Japan, Tokyo, Japan, 1990, vol. 2, pp. 548-57.

7. A. Poos: 6th Int. Iron and Steel Congr., Oct. 21-26, 1990, Nagoya, The Iron and Steel Institute of Japan, Tokyo, Japan, 1990, vol. 2, pp 395-404.

8. A.K. Biswas: Principles of Blast Furnace Ironmaking, Cootha Pub., Brisbane, Australia, 1981, p. 139.

9. D. Lathlean, K. Edwards, S. Webb, and R. Nightingale: ICSTI/Ironmaking Conf. Proc., 1998, pp. 193-202.
10. S. Wakuri, H. Kanoshima, M. Baba, T. Ashimura, M. Naito, and A. Hatanaka: AIME Ironmaking Conf. Proc., 1989, pp. 573-86.

11. R.R. Willmers and R.M. Poultney: Cokemaking Int., 1992, vol. 4 (1), pp. 69-78.

12. E. Beppler, B. Gerstenberg, U. Janhsen, and M. Peters: "Requirements on the Coke Properties Especially when Injecting High Coal Rates,' 1992 Ironmaking Conference Proceedings, Toronto, Canada, pp. 17184.

13. K. Sasaki, M. Hatano, M. Watanabe, T. Shimoda, K. Yokotani, T. Ito, and T. Yokoi: Tetsu-to-Hagané, 1976, vol. 62 (5), pp. 580-91.

14. K. Kambara, T. Hagiwara, A. Shigemi, S. Kondo, Y. Kanayama, K. Wakabayashi, and Y. Hiramoto: Tetsu-to-Hagané, 1979, vol. 62 (5), pp. 535-46.

15. K. Kojima, T. Nishi, T. Yamaguchi, H. Nakama, and S. Ida: Tetsu-toHagané, 1976, vol. 62 (5), pp. 570-79.

16. Y. Shimomura, Y. Kushima, and S. Arino: Report of 54th Committee of Gakushin, Japan Society for Promotion of Science, Tokyo, Japan, [Report No. 1484], 1979.

17. H. Takahashi, M. Tanno, and J. Katayama: Iron Steel Inst. Jpn. Int., 1996, vol. 36 (1), pp. 1354-59.

18. W.-K. Lu: in Advances in Physical Chemistry of Process Metallurgy, N. Sano, W.-K. Lu, and P. Riboud, Academic Press, London, 1997, pp. 219-47.

19. N. Tsuchiya, S. Taguchi, Y. Takada, and K. Okabe: Tetsu-to-Hagané, 1977, vol. 63, pp. 1791-1800.

20. H.W. Gudenau, L. Meier, and V. Schemmann: ICSTI/Ironmaking Conf. Proc., ISS, Toronto Canada, 1998, pp. 1068-72.

21. R.J. Nightingale, F.W.B.U. Tanzil, A.J.G. Beck, J.D. Dunning, and S.K. Vardy: ICSTI/Ironmaking Conf. Proc., ISS, Toronto, Canada, 1998. pp. 567-72.

22. R.J. Nightingale and F.W.B.U. Tanzil: Ironmaker and Steelmaker, 1997, Feb., pp. 1-3.

23. F. Neumann, H. Schenck, and W. Patterson: Geierei-Tech. Wiss. Beihefte, 1959, vol. 23, pp. 1217-46.

24. K.P. Galvin, R.J. Nightingale, and A.G. Waters: AusIMM Proc., 1994, vol. 299 (2), pp. 107-11.

25. B. McDonald, C. Wu, V. Sahajwall, K. Farrell, and T. Wall: ICST/ Ironmaking Conf. Proc., ISS, Toronto, Canada, 1998, pp. 1889-1900.

26. H.W. Gudenau, J.P. Mulanza, and D.G.R. Sharma: Steel Res., 1990, vol. 61 (3), pp. 97-104. 